\section{ASSISTING YOU WITH FISCAL DEMANDS}

accountants 4 dentists is a firm of chartered accountants and tax advisers who specialise in assisting dental professionals with the industry's fiscal demands.

accountants 4 dentists will be appearing at this year's British Dental Conference and Exhibition. Visitors to the accountants4dentists stand will have the opportunity to raise any monetary queries they have with a member of its highly experienced team on a broad range of financial topics.

accountants 4 dentists works closely with its sister company, money4dentists. By doing this both companies are able to share the knowledge they gain and pass on the benefits to their clients.

Visit accountants4dentists on stand K15 at this year's British Dental Conference and Exhibition and find out how they can help you.

For more information call 08453455060 or visit www.accountants4dentists.co.uk.

\section{PUT SOME SPARKLE INTO YOUR LAB WORK}

The recently opened Sparkle Dental Labs offers affordable high quality British laboratory work from experienced and dedicated technicians. Using the best materials available on all restorations for both their private and NHS customers, Sparkle Dental Laboratory is committed to quality and customer service.

The secret to Sparkle Dental Labs' outstanding service lies in the attention to detail and craftsmanship that is exerted in each and every product. All lab work takes place in Britain and every item is fully traceable, so you can be

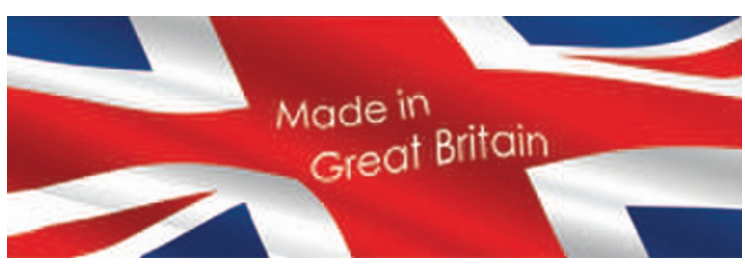

confident that you have received a high quality product and you know where it has come from.

Its success also lies in Sparkle Dental Labs' attention to providing exceptional customer service. Aware of the demands of running a dental practice, Sparkle Dental Labs offers a guaranteed three-day turn around policy on both NHS and private lab work, making life a little less hectic.

To find out more about Sparkle Dental Labs visit Genix Healthcare on stand E07 at this year's British Dental Conference and Exhibition or visit www. sparkledentallabs.com.

\section{THE SOLUTION FOR BIG SIZE CAVITIES}

The latest addition to the GC range is everX Posterior. This fibre-reinforced composite is designed to be used as dentine replacement, in conjunction with a conventional composite such as G-ænial Posterior used as enamel replacement. The short fibres of GC everX Posterior will make it a perfect sub-structure to reinforce any composite restoration in large size cavities. Fibres will also prevent and stop crack propagation through the filling, which is considered to be the main cause of composite failures. Thanks to its unique properties, GC everX Posterior opens new possibilities for restorations of extensive cavities at chairside and is the answer to the growing demand for an economic restorative alternative for big size cavities.
Advances in glass technology have resulted in the development of hand mixed GC Fuji IX GP EXTRA, a high strength glass-ionomer cement with a new generation of glass filler, resulting in a restoration with very high translucency that changes little over time. The result is natural aesthetics never before achievable with conventional glass ionomer.

Visit stand F02 at the Exhibition for a hands-on experience or for further information contact GC UK on 01908218999.
TOP QUALITY

\section{SEMINARS ON SITE}

For the first time, the Faculty of General Dental Practice (UK) (FGDP[UK]) is hosting a programme of top quality seminars at this year's British Dental Conference and Exhibition.

Leading dental professionals including Professor of Oral and Maxillofacial Imaging at Manchester University Keith Horner, and FGDP(UK)'s Course Director Paula McHenry will be speaking on a variety of topics from minor oral surgery to new radiology guidelines. Each session will last between an hour and 90 minutes.

Professor Stephen LambertHumble will be hosting a seminar on Dentists with Special Interests: how they were developed, what they are and what they do.

For full details of the FGDP(UK) Series programme, visit www.fgdp.org.uk.

\section{MICROSCOPES IN SHARP FOCUS}

Carl Zeiss dental microscopes are designed to allow those who use them a more ergonomic and anatomically correct posture minimising the potential of back or neck problems. At the British Dental Conference and Exhibition 2013 Nuview will be displaying the Carl Zeiss OPMI Pico and PROergo dental operating microscopes. Nuview will be on stand I12 and those who visit will be able to experience the superior vision and depth of magnification that only a Carl Zeiss dental microscope can provide.

Members of the Nuview team will also be on hand to discuss Continu, a range of fully HTM 01-05 compliant infection control solutions that are proven to eliminate more than 99.999\% of harmful microorganisms in no more than 30 seconds.

www.nuview.co 